\title{
Longitudinal and seasonal variation of stream $N$ uptake in an urbanizing watershed: effect of organic matter, stream size, transient storage and debris dams
}

\author{
Luc Claessens • Christina L. Tague • \\ Peter M. Groffman · John M. Melack
}

Received: 26 March 2009/Accepted: 9 September 2009/Published online: 6 October 2009

(C) The Author(s) 2009. This article is published with open access at Springerlink.com

\begin{abstract}
We examined seasonal and spatial linkages between $\mathrm{N}$ cycling and organic matter for a suburban stream in Maryland and addressed the question: How do longitudinal $\mathrm{NH}_{4}{ }^{+}$uptake patterns vary seasonally and what is the effect of organic matter, stream size, transient storage and debris dams? We applied a longitudinal (stream channel corridor) approach in a forested stream section and conducted short-term nutrient addition experiments (adapted to account for the effect of nutrient saturation) covering 14-16 reaches, and compared two distinct seasons (late fall 2003 and late summer 2004). Longitudinal
\end{abstract}

L. Claessens

Department of Geography, University of California, Santa Barbara, CA 93106, USA

L. Claessens

Department of Geography, San Diego State University,

San Diego, CA 92182, USA

L. Claessens $(\varangle)$

Department of Biological Systems Engineering, Virginia Tech, Blacksburg, VA 24061, USA

e-mail: luc.claessens@vt.edu

C. L. Tague · J. M. Melack

Donald Bren School of Environmental Science and

Management, University of California, Santa Barbara, CA

93106, USA

P. M. Groffman

Cary Institute of Ecosystem Studies, Millbrook, NY

12545, USA
$\mathrm{NH}_{4}{ }^{+}$uptake rate patterns had a distinct seasonal reversal; fall had the highest uptake rates in the upper reaches, while summer had the highest uptake rates in the lower reaches. This seasonal reversal was attributed to organic matter and evidenced by DON patterns. Transient storage did not have an expected effect on uptake rates in fall because it was confounded by leaf litter; litter produced higher uptakes, but also may have reduced transient storage. In summer however, uptake rates had a positive correlation with transient storage. Debris dams had no distinct effect on uptake in fall because of their recent formation. In summer however, the debris dam effect was significant; although the debris dams were hydraulically inactive then, the upstream reaches had $2-5$ fold higher uptake rates. The seasonal and longitudinal differences in $\mathrm{NH}_{4}{ }^{+}$uptake reflect interactions between flow conditions and the role of organic matter. Urbanization can alter both of these characteristics, hence affect stream $\mathrm{N}$ processing.

Keywords Debris dams · Nitrogen Nutrient additions · Organic matter . Streams · Transient storage

\section{Introduction}

Streams and riparian zones play an important role in reducing nitrogen loading from upland areas. Processes in riparian zones remove nitrogen before it 
enters surface waters and typically dominate on a watershed basis (Fenessy and Cronk 1997). Small headwater streams can be important as well (e.g., Alexander et al. 2007) and there is evidence of significant (in some cases more than half of in-stream nitrogen) uptake (Peterson et al. 2001). Numerous studies have shown that there are multiple controls on in-stream uptake, including both biotic and abiotic factors. Most of these controls vary in space and time. Within headwater streams, spatial-temporal variation in channel form, discharge and other characteristics may lead to hot spots and hot moments of nitrogen cycling and uptake (McClain et al. 2003). The question that arises is: where and when does nutrient uptake occur and what are the critical controls? This geographical question becomes important when targeting stream restoration efforts and land-use management practices, particularly given that nutrient processing in small headwater streams can be affected by urban and suburban development (Paul and Meyer 2001; Walsh et al. 2005). Headwater streams in these settings receive increased loads of nitrogen. In addition, increases in peak discharge and flashiness of flow (Leopold 1968) lead to increased rates of stream incision (Hammer 1972) which can result in upland flows bypassing the riparian zone and changes in channel form and in-stream flow characteristics (Groffman et al. 2003).

Numerous studies have been conducted on instream nitrogen processing, with relatively few studies in suburban streams (e.g., Mulholland et al. 2008). When applied at a whole-stream scale these studies are often based on the concept of nutrient spiraling (Webster and Patten 1979; Newbold et al. 1981; Elwood et al. 1983) (see Ensign and Doyle 2006, for review). The associated field experiments typically involve isotopic tracer or nutrient additions and adopt a stream reach as the defining spatial unit. Most studies have focused on comparing reaches with distinct characteristics (hydrological, geomorphological and biological) across a range of sites. However, few studies have examined nitrogen processing through a stream channel corridor. Such longitudinal studies are considered essential for understanding the downstream fate of nitrogen (Alexander et al. 2007), as well as the associated ecological linkages with organic matter and biological communities (Wipfli et al. 2007). Within this spatial context, temporal examinations can further elucidate changes in endogenous and exogenous controls on in-stream nitrogen cycling (Valett et al. 2008).

Stream size is an important factor in the downstream fate of nitrogen (Alexander et al. 2000; Peterson et al. 2001; Wollheim et al. 2001), as it influences both physical and biological stream characteristics (Vannote et al. 1980). Smaller streams have larger surface area to volume ratios, hence more contact between water column and streambed. Also, smaller streams tend to have lower velocities, hence more contact time between water column and streambed. Both effects typically result in smaller streams having high uptake relative to transport, forming the basis for empirical regional-scale models of nitrogen uptake and retention (e.g., Howarth et al. 1996; Smith et al. 1997; Seitzinger et al. 2002).

Much in-stream processing of nitrogen is thought to take place in the hyporheic zone, the subsurface flowpaths along which stream water mixes with subsurface water. This zone is considered a biogeochemical hot spot (McClain et al. 2003) and hyporheic exchange and its importance for biogeochemical transformations has received increased attention (e.g., Jones and Mulholland 2000). Urbanization and associated changes in stream channel morphology likely reduce hyporheic exchange (Paul and Meyer 2001), while urban stream restoration can significantly increase hyporheic nitrogen processing (Kaushal et al. 2008). At the reach-scale, hyporheic exchange is typically characterized with transient storage (TS) models (e.g., Bencala and Walters 1983; Runkel 1998); note however, that TS includes both hyporheic exchange and surface storage. Interestingly, single site studies relating TS and nutrient uptake have been equivocal (Hall et al. 2002; Roberts et al. 2007). In the most extensive study, Hall et al. (2002) found that ammonium uptake was strongly related with TS in summer only.

In small streams, organic debris dams can play an important role in regulating the export of particulate organic matter (Bilby and Likens 1980) and can serve as hot spots of biogeochemical cycling (Valett et al. 2002; Groffman et al. 2005). The reduction in flow velocity when debris dams are hydraulically active enhances both organic matter accumulation and water/sediment contact time. Therefore, debris dams can have an important controlling function on watershed nutrient export. The formation and biogeochemical functioning of debris dams is affected 
by both long-term processes (e.g., forest succession, Valett et al. 2002) and episodic events (e.g., icestorm, Bernhardt et al. 2003).

We conducted several studies to examine the role of small streams in controlling nitrogen export from a suburbanizing watershed in Maryland. In this study we examined seasonal and spatial linkages between nitrogen cycling and organic matter and addressed the following question: How do longitudinal ammonium $\left(\mathrm{NH}_{4}{ }^{+}\right)$uptake patterns vary seasonally and what is the effect of organic matter, stream size, transient storage and debris dams? We applied a longitudinal (stream channel corridor) approach in a forested stream section and conducted short-term nutrient addition experiments adapted to account for the effect of nutrient saturation (Claessens and Tague 2009). We compared two distinct seasons (late fall 2003 and late summer 2004). Although nitrate $\left(\mathrm{NO}_{3}{ }^{-}\right)$is the dominant nitrogen species of concern in our study area, in this paper we focused on $\mathrm{NH}_{4}{ }^{+}$because it is cycled more rapidly which facilitates the detection of controlling relationships at relatively fine spatial scales. In a separate paper (Claessens et al. 2009a) we examine longitudinal variation in $\mathrm{NO}_{3}{ }^{-}$uptake and how it is affected by concentration.

\section{Study area}

The study was conducted on the main stem of Baisman Run (BARN), located in Baltimore County in Maryland, about 15 kilometers north of the city of Baltimore (Fig. 1). The $3.8 \mathrm{~km}^{2}$ BARN watershed is one of several watersheds monitored as part of the Baltimore Ecosystem Study Long Term Ecological Research program (BES-LTER). Land-use in the BARN watershed is characterized by low-density residential in the upper portion and forested in the lower portion (Fig. 1). All developments in the headwaters are on septic systems. The forested lower watershed is part of Oregon Ridge, a Baltimore County park that has been subject to logging and agriculture in the past. Currently, the forest vegetation is dominated by $80-100$ year old chestnut oaks (Quercus prinus) on the hill slopes and divides, and tulip poplars (Liriodendron tulipifera) on the floodplains (Groffman et al. 2006). BARN is particularly suited for investigating in-stream processing, as it has a step change in nitrate loading, with high loadings from the upper, developed portion and low loadings from the lower, forested portion. The BARN watershed has been the focus of several studies to examine nitrogen fluxes (Groffman et al. 2004) and

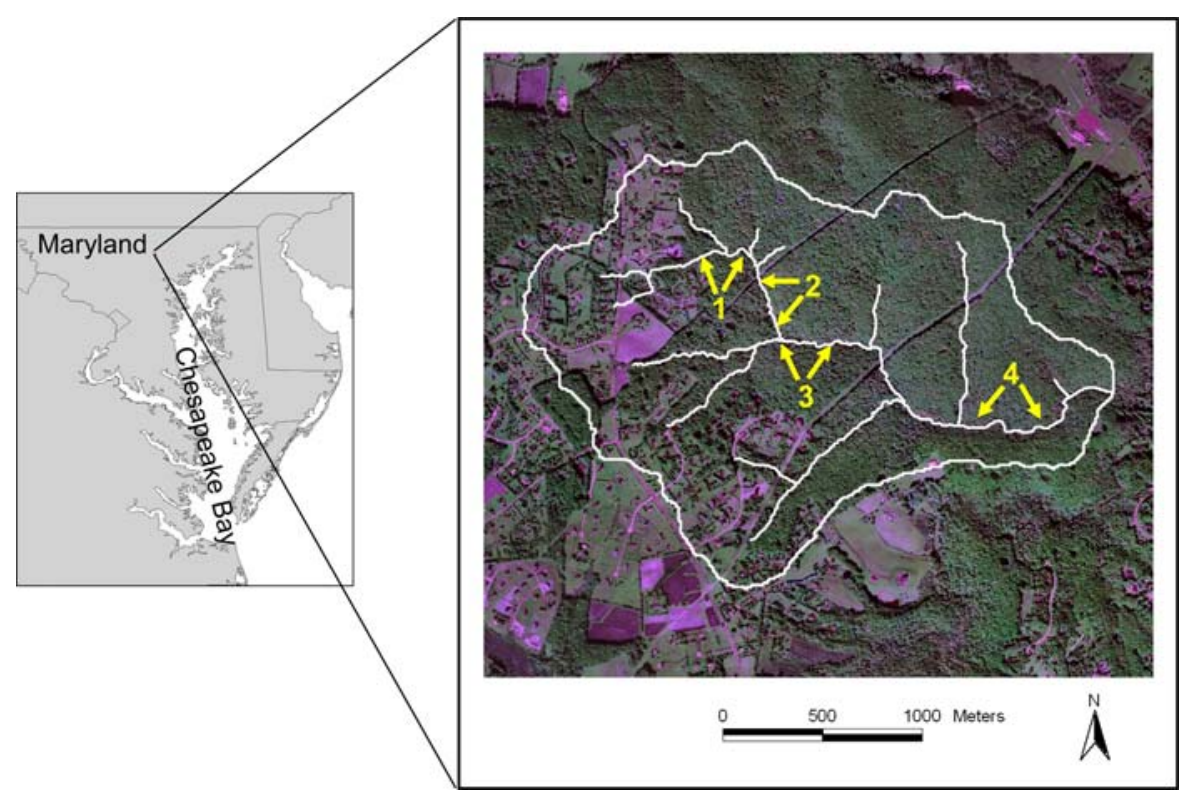

Fig. 1 Baisman Run watershed with stream network (false color image using EMERGE digital aerial imagery). Lighter colored areas in the headwaters indicate development. Numbered sections correspond to location of nutrient addition experiments 
the role of small streams in controlling nitrogen export from suburban land-use (Claessens et al. 2009a, 2009b).

The BARN watershed lies in the eastern Piedmont and is underlain by metasedimentary rocks (schist). The topography varies from gently sloping to hilly, with locally steep slopes near drainage channels. The stream geomorphology is generally characterized by locally incised cross sections in the upper watershed (because of development-induced erosion); meanders, floodplains and relic streambeds in the mid-watershed; and occasional bedrock outcrops and rapids in the lower watershed. The streambed is dominated by sand and cobble substratum in the upper watershed; sand, pebble and cobble substratum in the mid-watershed; and even distribution of sand, gravel, pebble and cobble substratum in the lower watershed (based on $10 \mathrm{~m}$ survey). The stream is predominantly heterotrophic; high-stature riparian vegetation reduces autotrophic production by shading and produces inputs of allochthonous organic matter. In September 2003, Hurricane Isabel (degraded to a tropical storm) produced heavy winds that knocked down many trees. This led to the formation of numerous debris dams. Evaluating the effect of debris dams played an important role in the design of our study.

\section{Methods}

The nutrient addition experiments reported here were conducted in late fall 2003 and late summer 2004. To estimate $\mathrm{NH}_{4}{ }^{+}$uptake we used OTIS-MM (Claessens and Tague 2009), a transport-based nutrient addition approach adapted to account for the effect of nutrient saturation. We specifically designed the field experiments for this new field-modeling approach. We used transient storage (TS) as a surrogate for the hyporheic zone, while acknowledging that TS includes both hyporheic exchange and surface storage. We used short-term additions of a conservative solute (bromide) to estimate transport and TS characteristics, using the One-dimensional Transport with Inflow and Storage (OTIS) solute transfer model (Runkel 1998).

The fall 2003 experiments were conducted $\sim 1$ month after leaf fall. Leaf litter affects biotic $\mathrm{NH}_{4}{ }^{+}$uptake because of increased immobilization (e.g., Tank and Webster 1998) and hence can confound the relationship between $\mathrm{NH}_{4}{ }^{+}$uptake and stream size. Fortunately, due to major storm events large amounts of leaf litter had been purged from the stream prior to the experiments and the amount of leaf litter during the fall experiments was similar to winter conditions (based on visual observation). Less leaf litter was present in summer 2004 due to ensuing downstream transport and biological and physical breakdown. Also, the fall experiments were conducted $\sim 2$ months after the formation of numerous organic debris dams. Depending on flow conditions, debris dams are hydraulically active or inactive. They were active in fall, slowing down flow and trapping sediment and particulate organic matter, but were inactive in summer when flows were lower.

\section{Nutrient addition experiments}

We conducted two seasonal sets of short-term nutrient addition experiments in the main stem of BARN. The first set of experiments (16 reaches) was performed in late fall 2003, several weeks after leaf fall. The second set of experiments (14 reaches) was performed in late summer 2004; experiments were repeated for all but two of the same reaches. The reaches were selected based on the presence of distinct stream characteristics (e.g., debris dams), the location of confluences, and ease of access. Reaches ranged in length from 20 to $100 \mathrm{~m}$ and had travel times of $\sim 0.2-0.4 \mathrm{~h}$ in fall 2003 and $0.3-0.8 \mathrm{~h}$ in summer 2004. All 14-16 reaches were covered in 4 days of experiments, with a single addition covering 3-5 sequential reaches. Hereafter, we refer to all the reaches that were covered in one single addition as a "section." The first day addition was at the most upstream section, moving downstream in the following days.

Prior to the experiments we estimated stream flow and travel time. Streamflow was measured with a propeller-type flowmeter (Swoffer) and travel time for each reach was estimated by timing the front- and tailend of a fluorescent dye plume (Rhodamine WT). From these measurements we determined the injectate concentration, the injection duration and the sampling times at each station. The injectate concentration was aimed at raising $\mathrm{Br}^{-}$background by $2-3 \mathrm{mg} \mathrm{L}^{-1}$ (background was $0.003-0.12 \mathrm{mg} \mathrm{L}^{-1}$ ) and $\mathrm{NH}_{4}^{+}$ background by $180 \mu \mathrm{g} \mathrm{N} \mathrm{L}^{-1}$ (background was 2-16 $\mu \mathrm{g} \mathrm{N} \mathrm{L}{ }^{-1}$ ). For $\mathrm{NH}_{4}^{+}$this increase in background concentration is higher than what is typical in 
traditional short-term nutrient additions; this allowed us to cover multiple, sequential reaches in one addition. For the injection duration we aimed for at least $1 / 2 \mathrm{~h}$ (fall 2003) or $2 \frac{1}{2} \mathrm{~h}$ (summer 2004) plateau duration for the most downstream reach. The OTISMM nutrient addition approach involved sampling over the rising part of the breakthrough curve (solute concentration curve). Sampling times at each station were specifically designed to reduce uncertainty in estimating transport, TS and uptake parameters and to improve calibration convergence of the OTIS-MM model (i.e., samples were concentrated in parts of the breakthrough curve that most strongly relate to dispersion, advection, dilution, TS and uptake).

Sodium bromide and ammonium chloride were dissolved in DI water in the lab, transported in carboys to the field and injected using a peristaltic pump (Wheaton) powered by a marine battery. The pump was calibrated before each injection and checked post-injection (flow rate deviations were less than 1\%). The solute was injected at a natural or temporary artificially constructed flow constriction, followed by a 20-25 m mixing reach. Sampling stations were located at upstream and downstream reach boundaries. Water samples for bromide and nutrients were collected as grab samples in the thalweg, always in the same spot. Station operators were equipped with synchronized watches and collected samples at specified times. At each station 13 samples were collected in fall 2003 and 18 samples in summer 2004. The grab samples were collected using $250 \mathrm{ml}$ plastic sample bottles that had been acidwashed and rinsed with stream water, and were immediately filtered $(0.7 \mu \mathrm{m}$ Whatman GF/F) using syringes and filter holders into $20 \mathrm{ml}$ plastic scintillation vials that had been rinsed with filtered sample water. The samples were placed on ice and upon return from the field were kept either refrigerated (bromide) or frozen (nutrients).

Both sets of experiments were conducted during baseflow conditions. The additions started early in the morning and sampling was completed by early afternoon. Diurnal fluctuations in flow (because of evapotranspiration) were substantial in summer 2004 ( $\sim 10 \%$ decrease during the experiment) and were accounted for during the calibration of the OTIS model parameters (Claessens and Tague 2009). Stream temperatures were measured over the course of the experiments in fall 2003. Wetted stream widths were measured every $10 \mathrm{~m}$ for a representative crosssection and visual stream surveys were conducted every $10 \mathrm{~m}$ to record streambed substratum, flow type, habitat and debris.

Bromide samples were analyzed on an ion chromatograph (Dionex DX-120) at the MBL Ecosystems Center in Woods Hole, MA. Nutrient samples were analyzed on a Lachat autoanalyzer at the Cary Institute of Ecosystem Studies in Millbrook, NY. Samples were run out of sequence to reduce analytical artifacts introduced by instrument drift and changes in standards and reagents.

\section{Data analysis}

\section{Transport and transient storage}

Transport and TS parameters for each reach were estimated from the $\mathrm{Br}^{-}$concentrations using the OTIS solute transport model (Runkel 1998), which is based on the Bencala and Walters (1983) TS model. The following parameters were estimated: stream channel cross-sectional area $(A)$, storage zone cross-sectional area $\left(A_{\mathrm{s}}\right)$, dispersion coefficient $(D)$ and storage zone exchange coefficient $(\alpha)$. Parameters were estimated using a semi-automatic, nonlinear least square algorithm as part of OTIS-P. After model calibration we calculated several transport and TS metrics. We calculated reach travel time $(T)$ over water depth $(h)$, $T / h$, which is inversely related to specific discharge (discharge per unit width). $T / h$ is an approximate measure of contact between water column and streambed and is commonly used in estimating nitrogen removal (e.g., Seitzinger et al. 2002). We calculated the relative size of the TS zone $\left(A_{\mathrm{s}} /\left(A+A_{\mathrm{s}}\right)\right)$. We also calculated the fraction of median reach travel time due to TS $\left(F_{m e d}\right)$, a transport-based TS metric introduced by Runkel (2002). Because we were interested in comparing reaches with distinct flow characteristics (e.g., debris dam reaches), we calculated $F_{\text {med }}$ by adopting a standardized median reach travel time of $18 \mathrm{~min}\left(F_{\text {med }}^{T 18}\right)$ (18 min was the average value of the median reach travel times for all the reaches).

\section{Ammonium uptake}

$\mathrm{NH}_{4}{ }^{+}$uptake parameters for each reach were estimated using OTIS-MM. See Claessens and Tague (2009) for governing equations and method details. 
The following OTIS-MM parameters were estimated: lateral inflow reactive solute concentration $\left(C_{\mathrm{L}}\right)$, maximum uptake rate $\left(U_{\max }\right)$ and half-saturation constant $\left(K_{\mathrm{s}}\right)$. Note that $C_{\mathrm{L}}$ is different from the background concentration, which is affected by uptake. Parameters were estimated using a semiautomatic, nonlinear least square algorithm built into OTIS-P, as well as through manual calibration. For each experiment, iterative calibrations were performed until convergence was achieved for all parameters in all reaches.

\section{Ammonium uptake metrics}

We calculated the following interrelated uptake metrics (Stream Solute Workshop 1990):

$$
\begin{aligned}
S_{w} & =\frac{u}{K_{c}} \\
U & =h K_{c} C \\
V_{f} & =h K_{c}
\end{aligned}
$$

where $K_{c}$ is first-order uptake rate constant $\left[\mathrm{T}^{-1}\right]$, which describes uptake on a volumetric basis; $S_{w}$ is uptake length [L], which is the average travel distance of nutrients before removal; $U$ is uptake rate $\left[\mathrm{M} \mathrm{L}^{-2} \mathrm{~T}^{-1}\right]$, which describes uptake rate per unit area of stream bottom; $V_{f}$ is uptake velocity $\left[\mathrm{L} \mathrm{T}^{-1}\right]$, which describes the vertical velocity of nutrients towards the benthos; $C$ is concentration $\left[\mathrm{M} \mathrm{L}^{-3}\right] ; u$ is velocity $\left[\mathrm{L} \mathrm{T}^{-1}\right]$; and $h$ is water depth [L]. Fundamental units are mass $[\mathrm{M}]$, length $[\mathrm{L}]$ and time [T]. These basic uptake metrics are based on first-order kinetics and are not transport-based. To calculate these metrics, we used a simulation approach using OTIS-MM. First, we estimated median velocity $(u)$ from OTIS. Next, we calculated uptake lengths $\left(S_{w}\right)$ for a sequence of OTIS-MM simulations. Similar to empirical methods (e.g., Webster and Ehrman 1996), we determined $S_{w}$ by regressing plateau concentrations against distance, after correcting for background and dilution. A total of 6 simulations were performed with increasing levels of solute addition, from which we estimated $S_{w}$ at background concentration through extrapolation (similar to the approach suggested by Dodds et al. 2002). Uptake rate constant $\left(K_{c}\right)$, uptake rate $(U)$ and uptake velocity $\left(V_{f}\right)$ were calculated subsequently using Eq. 1.

The OTIS-MM approach solves for lateral inputs, which allows for calculating reach-scale mass balances, hence uptake. Proportional uptake over the reach $(R)$ was calculated by mass balance:

$R=\frac{\left(M_{I}+M_{L}\right)-M_{O}}{M_{I}+M_{L}}$

where $R=$ proportional uptake over the reach; $M_{I}$ is mass of $\mathrm{NH}_{4}{ }^{+}$input at top of reach; $M_{O}$ is mass of $\mathrm{NH}_{4}{ }^{+}$output at bottom of reach; and $M_{L}$ is mass of $\mathrm{NH}_{4}{ }^{+}$input along reach as lateral input. Lateral input includes both $\mathrm{NH}_{4}{ }^{+}$input in lateral flow as well as recycling of $\mathrm{NH}_{4}{ }^{+}$uptake (remineralization). The latter constitutes the major portion of lateral input (typically, remineralization is assumed to be equal to uptake).

Most of the reaches (except a few debris dam reaches) were similar in length $(80-100 \mathrm{~m})$. Through model simulations we determined that the slight differences in reach lengths had only a minor effect on relationships with reach length dependent variables, including travel time $(T)$ and uptake $(R)$. Therefore, instead of adopting a uniform reach length and using model simulations, we calculated $T$ and $R$ based on the actual reach lengths.

\section{Statistical analysis}

We tested for statistical correlations between seasons for the various hydrologic, TS and uptake terms. We also tested for correlations between uptake terms, and hydrological and TS terms. We used a rank-based nonparametric test, Kendall's tau (Kendall 1975). Because debris dam reaches differed in physical and biological characteristics, we performed separate statistical analyses using all the reaches, and using a subset of non-debris dam reaches only.

\section{Results}

Physical and hydrologic characteristics

Physical and hydrologic characteristics for the fall 2003 and summer 2004 experiments are presented (Table 1; Fig. 2a-c) and were tested for seasonal correlation (Table 2). Discharge was about twice as high in fall compared to summer (Table 1). Crosssectional areas (solved by OTIS) were larger in fall, partly because of active debris dam reaches. Both measured wetted stream widths and water depths were also larger in fall, while median velocities were 


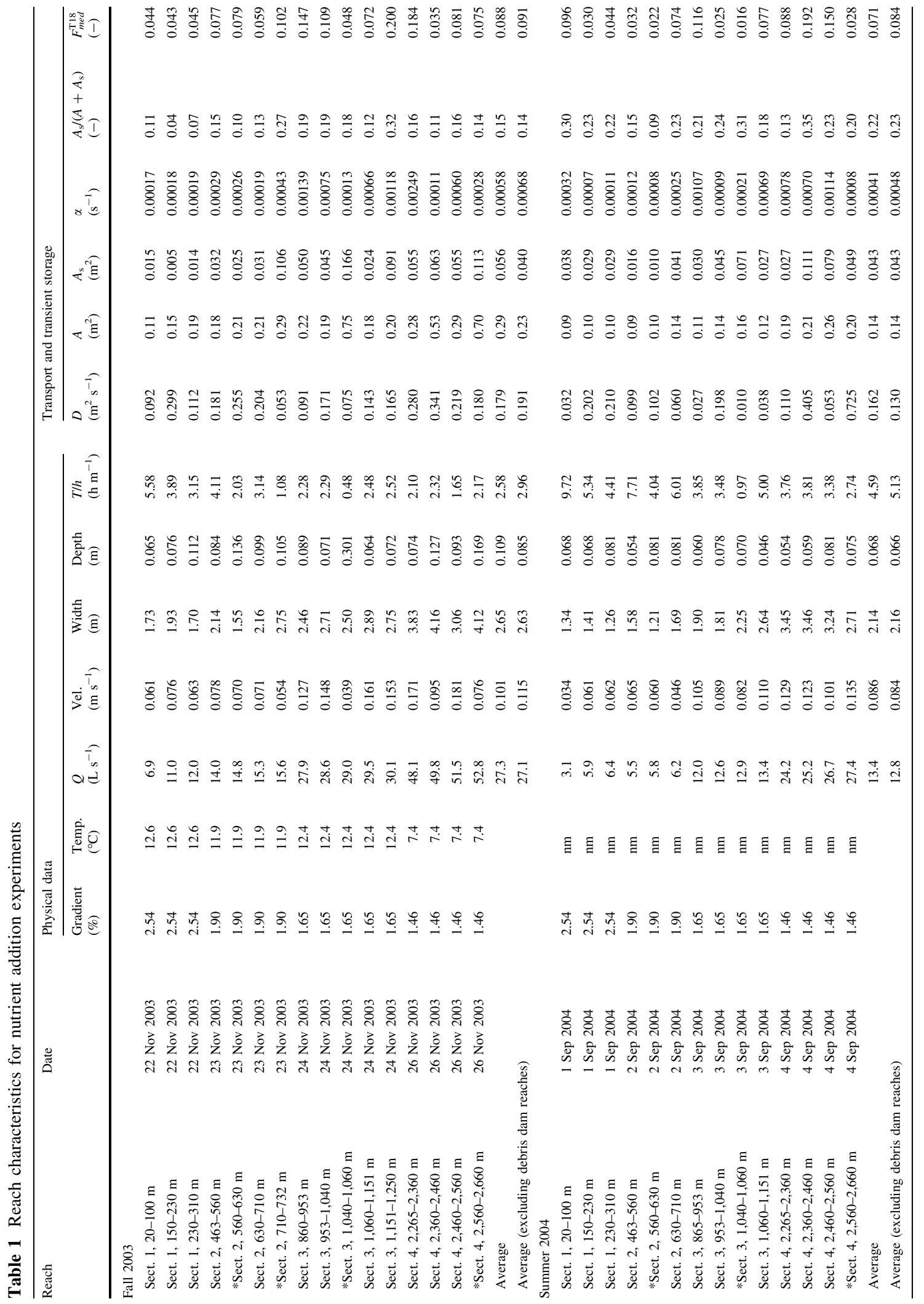




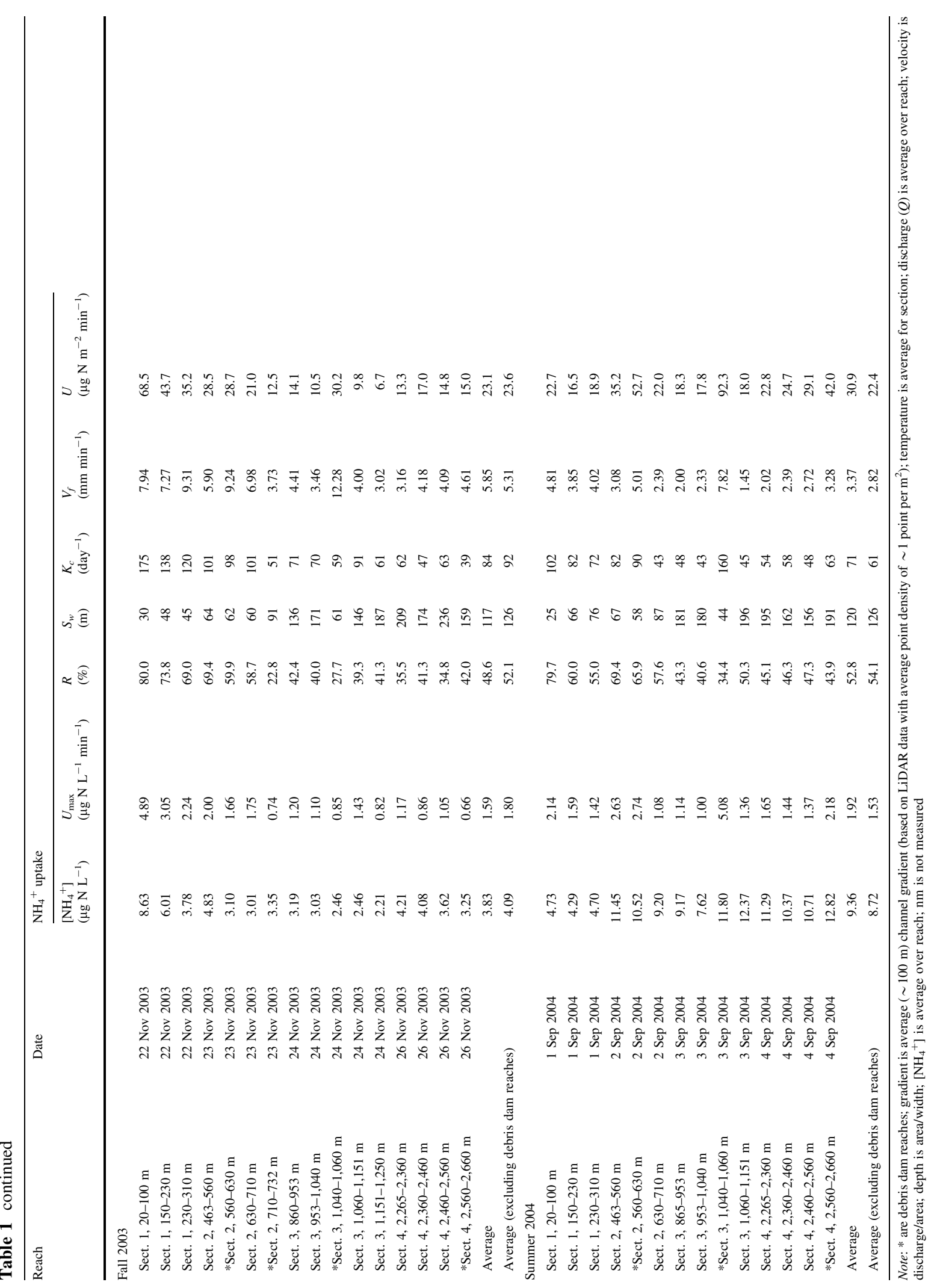




\section{Transport and Transient Storage}

(a)

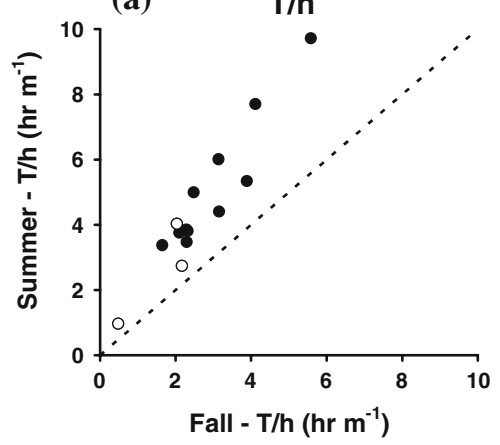

Saturation Limited Uptake

(d)

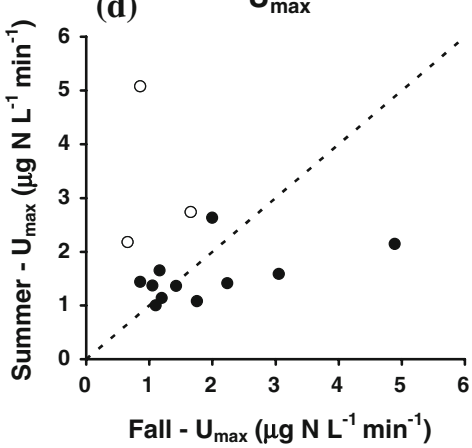

First Order-Derived Uptake

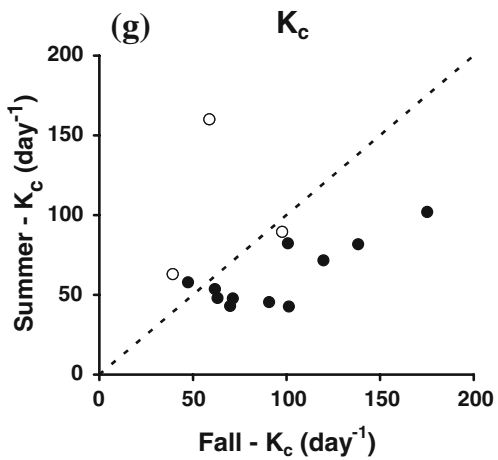

(b)

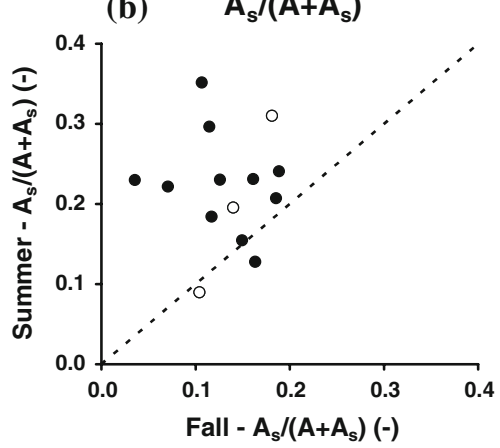

(e)
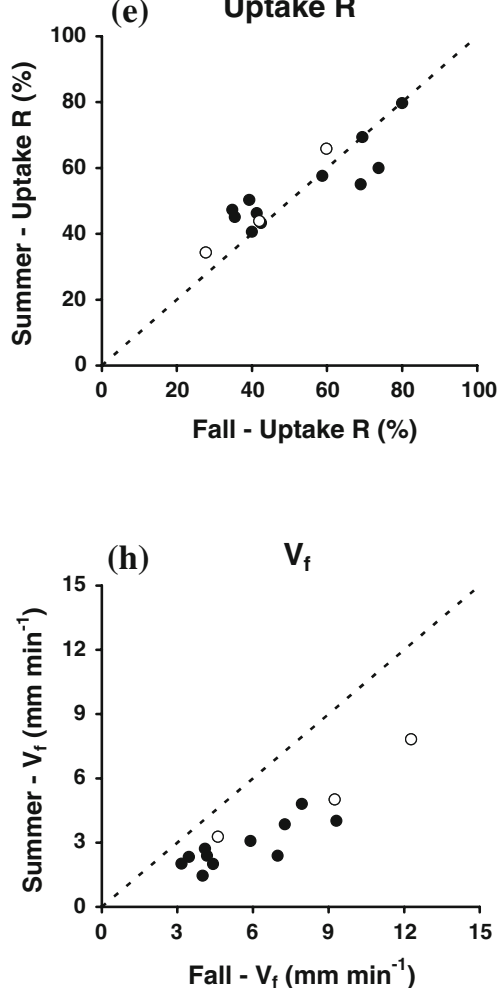

(c) $\quad \mathrm{F}_{\text {med }}{ }^{\mathrm{T} 18}$

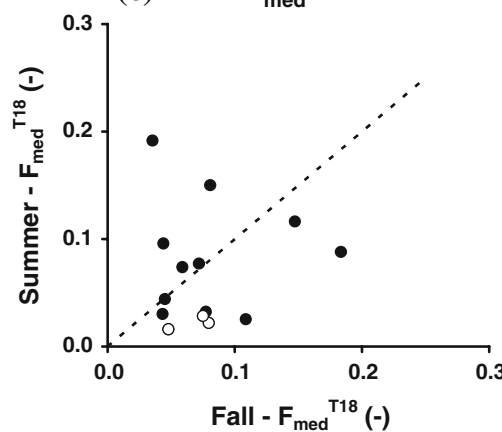

(f)

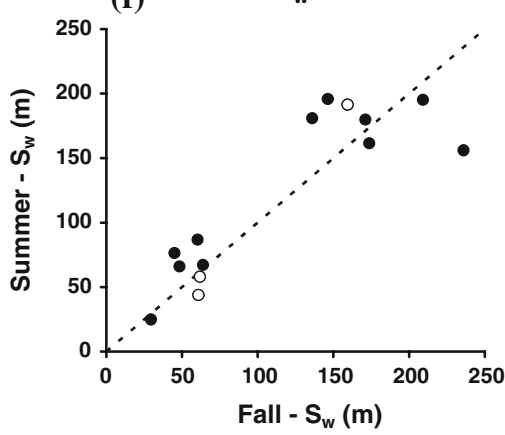

Fig. 2 Seasonal comparison (summer 2004 vs. fall 2003) of various hydrologic terms and $\mathrm{NH}_{4}{ }^{+}$uptake terms for each reach. Open symbols are debris dam reaches. Dotted line is 1:1 line

similar between seasons. Travel time over water depth $(T / h)$ was larger in summer (Fig. 2a), reflecting a combination of lower velocities (i.e., longer travel time) and smaller water depths. Spatial (between reach) patterns of $T / h$ correlated between seasons $(p<0.001)$.

The relative size of the TS zone $\left(A_{\mathrm{s}} /\left(A+A_{\mathrm{s}}\right)\right)$ was smaller in fall (Fig. 2b), indicating that with higher flows the relative size of TS diminished (likely because of stronger groundwater gradients towards the stream $) . A_{\mathrm{s}} /\left(A+A_{\mathrm{s}}\right)$ had a larger range when flow was low and spatial (between reach) patterns did not correlate between seasons. The relative time that water spent in TS $\left(F_{\text {med }}^{T 18}\right)$ was similar between seasons (Fig. 2c) and again spatial patterns did not correlate between seasons. In summer only, $F_{\text {med }}^{T 18}$ generally 
Table 2 Nonparametric correlations between seasons for hydrologic, TS and uptake terms (Kendall's $\tau$ and probability)

\begin{tabular}{|c|c|c|c|c|}
\hline \multirow[t]{2}{*}{ Variables } & \multicolumn{2}{|c|}{ All reaches } & \multicolumn{2}{|c|}{ Subset reaches } \\
\hline & $\tau$ & $p$ & $\tau$ & $p$ \\
\hline$Q$ & 0.89 & $<0.001$ & 0.89 & $<0.001$ \\
\hline$T / h$ & 0.71 & $<0.001$ & 0.78 & $<0.001$ \\
\hline$A_{\mathrm{s}} /\left(A+A_{\mathrm{s}}\right)$ & 0.03 & 0.43 & -0.16 & 0.24 \\
\hline$F_{m e d}^{\mathrm{T} 18}$ & -0.03 & 0.43 & -0.02 & 0.47 \\
\hline$U_{\max }$ & -0.03 & 0.43 & 0.27 & 0.12 \\
\hline$R$ & 0.58 & $<0.01$ & 0.56 & $<0.01$ \\
\hline$S_{w}$ & 0.47 & $<0.01$ & 0.49 & 0.02 \\
\hline$K_{c}$ & 0.03 & 0.43 & 0.20 & 0.20 \\
\hline$V_{f}$ & 0.71 & $<0.001$ & 0.64 & $<0.01$ \\
\hline$U$ & 0.21 & 0.15 & 0.13 & 0.29 \\
\hline
\end{tabular}

Note subset excludes debris dam reaches; bold indicates significance $(p<0.05)$

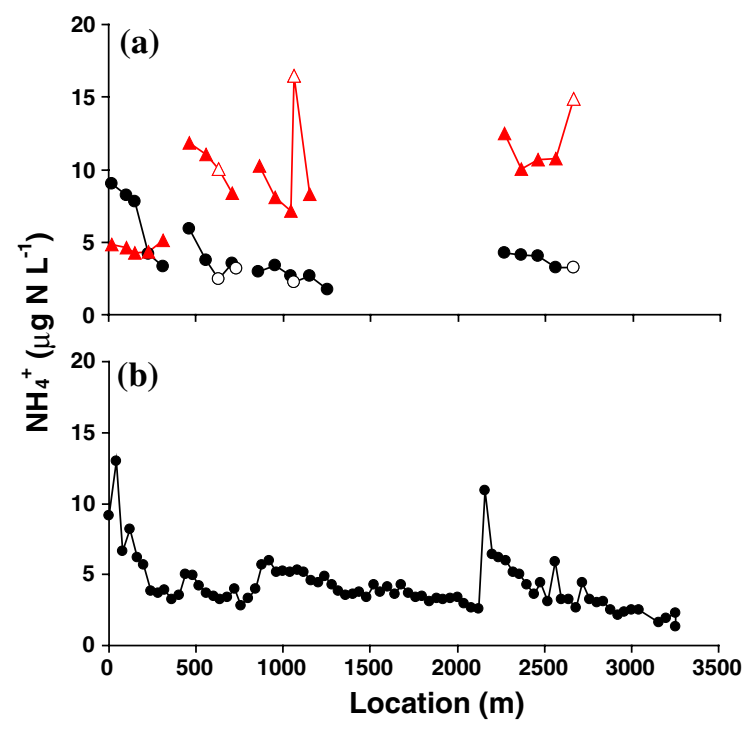

Fig. 3 a Background $\mathrm{NH}_{4}{ }^{+}$concentrations for reach sampling locations; b Background $\mathrm{NH}_{4}{ }^{+}$concentrations for detailed synoptic (40 m) for fall 2003. Circles are fall 2003; triangles are summer 2004; open symbols are debris dam reaches

increased downstream (results not shown). The debris dam reaches in summer had the lowest values for $F_{\text {med }}^{\text {T18 }}$ (Fig. 2c).

\section{Chemical characteristics}

Background $\mathrm{NH}_{4}{ }^{+}$concentrations in fall 2003 were generally lower compared to summer 2004 (Fig. 3a). There was a slight downstream decrease in $\mathrm{NH}_{4}^{+}$
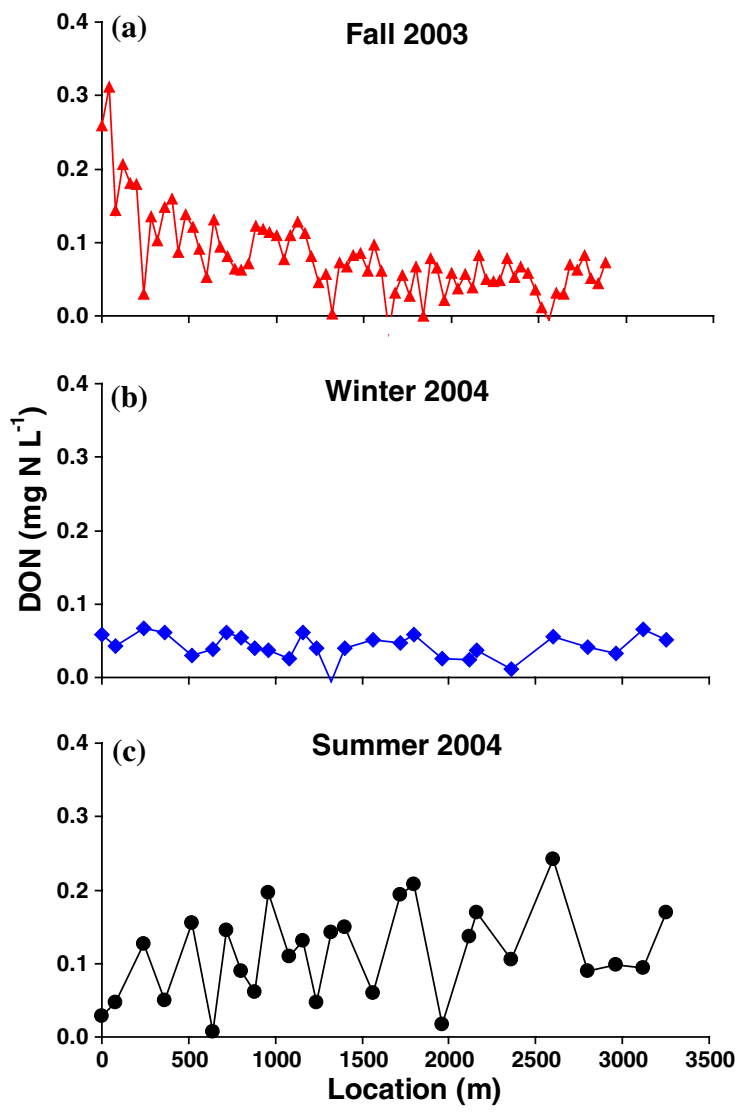

Fig. 4 DON concentrations for detailed synoptic: a November 25, 2003; b March 5, 2004; c September 6, 2004

concentration in fall. Detailed synoptic (40 m resolution) $\mathrm{NH}_{4}{ }^{+}$patterns (Fig. 3b) illustrate that tributaries can shift the baseline concentration (e.g., increased concentrations downstream of the confluence of Pond Branch at 2,140 m), but the overall pattern was a general downstream decrease in $\mathrm{NH}_{4}{ }^{+}$concentration. While fall 2003 had a downstream decrease in $\mathrm{NH}_{4}{ }^{+}$ concentration, summer 2004 had a slight increase (Fig. 3a). This increase can be attributed to some extent to tributary inputs. Dissolved organic nitrogen (DON) concentration profiles had a distinct seasonal reversal (Fig. 4): in fall, DON rapidly decreased downstream (particularly over the upper and middle reaches); in winter, DON had no downstream trend; and in summer, DON gradually increased downstream.

Ammonium uptake

Debris dams can change transport, TS and uptake characteristics. When reporting patterns we refer to 
the subset of non-debris dam reaches only, except when we specifically address the debris dam reaches.

\section{Seasonal comparison}

$U_{\max }, K_{c}, V_{f}$ and $U$ behaved similarly in terms of seasonal comparison between fall and summer. They were larger in fall compared to summer (Table 1; Fig. 2); had a larger range in fall (Fig. 2); and between reach patterns did not correlate between seasons, except for $V_{f}$ which correlated $(p<0.01)$. $R$ was similar in summer compared to fall (Table 1; Fig. 2); had a similar range in fall and summer (Fig. 2); and between reach patterns correlated between seasons $(p<0.01) . S_{w}$ was also similar in summer compared to fall (Table 1; Fig. 2); had a similar range in fall and summer (Fig. 2); and between reach patterns correlated between seasons $(p=0.02)$.

\section{Correlation with hydrologic and TS terms}

$U_{\max }, K_{c}, V_{f}$ and $U$ behaved similarly in terms of correlation with hydrologic and TS terms (Table 3). They had a negative relationship with discharge in fall $(p<0.01)$ and no relationship in summer; a positive relationship with $T / h$ in fall $(p<0.02)$ and no relationship in summer; and a negative relationship with $F_{m e d}^{T 18}$ in fall $(p<0.02)$ and no relationship in summer, except for $U$ which had a positive relationship with $F_{m e d}^{T 18}$ in summer $(p=0.05)$. Figure 5 illustrates the distinct seasonal relationships between $U$ and stream size, transport and TS. $R$ had a negative relationship with discharge in both fall $(p<0.001)$ and summer $(p<0.01)$; a positive relationship with $T / h$ in both fall $(p<0.001)$ and summer $(p<0.01)$; and a negative relationship with $F_{\text {med }}^{T 18}$ in fall $(p=0.05)$ and no relationship in summer. Figure 5 illustrates the distinct seasonal relationships between $R$ and stream size, transport and TS. $S_{w}$ had a positive relationship with discharge in both fall $(p<0.001)$ and summer $(p=0.01)$; a negative relationship with $T / h$ in both fall $(p<0.01)$ and summer $(p=0.04)$; and a positive relationship with $F_{\text {med }}^{T 18}$ in fall $(p=0.02)$ and no relationship in summer.

\section{Debris dam reaches}

Compared to other reaches in longitudinal proximity, debris dam reaches had similar values for $U_{\max }, K_{c}$, $V_{f}$ and $U$ in fall; in contrast, they had higher values in summer (Fig. 2 and 3 ). When relating $U$ to $F_{\text {med }}^{T 18}$ (Fig. 5c), in fall the debris dam reaches were not distinct from other reaches; they were distinct in

Table 3 Nonparametric correlations between uptake terms, and hydrologic and TS terms (Kendall's $\tau$ and probability)

\begin{tabular}{|c|c|c|c|c|c|c|c|c|c|c|c|c|}
\hline \multirow[t]{3}{*}{ Variables } & \multicolumn{4}{|l|}{$Q$} & \multicolumn{4}{|l|}{$T / h$} & \multicolumn{4}{|l|}{$F_{\text {med }}^{\mathrm{T} 18}$} \\
\hline & \multicolumn{2}{|c|}{ All reaches } & \multicolumn{2}{|c|}{ Subset reaches } & \multicolumn{2}{|c|}{ All reaches } & \multicolumn{2}{|c|}{ Subset reaches } & \multicolumn{2}{|c|}{ All reaches } & \multicolumn{2}{|c|}{ Subset reaches } \\
\hline & $\tau$ & $p$ & $\tau$ & $p$ & $\tau$ & $p$ & $\tau$ & $p$ & $\tau$ & $p$ & $\tau$ & $p$ \\
\hline \multicolumn{13}{|l|}{ Fall 2003} \\
\hline$U_{\max }$ & -0.67 & $<0.001$ & -0.79 & $<0.001$ & 0.55 & $<0.01$ & 0.58 & $<0.01$ & -0.33 & 0.04 & -0.45 & 0.02 \\
\hline$R$ & -0.55 & $<0.01$ & -0.82 & $<0.001$ & 0.67 & $<0.001$ & 0.79 & $<0.001$ & -0.28 & 0.06 & -0.36 & 0.05 \\
\hline$S_{w}$ & 0.72 & $<0.001$ & 0.85 & $<0.001$ & -0.30 & 0.05 & -0.64 & $<0.01$ & 0.48 & $<0.01$ & 0.45 & 0.02 \\
\hline$K_{c}$ & -0.68 & $<0.001$ & -0.79 & $<0.001$ & 0.53 & $<0.01$ & 0.58 & $<0.01$ & -0.32 & 0.04 & -0.52 & $<0.01$ \\
\hline$V_{f}$ & -0.38 & 0.02 & -0.61 & $<0.01$ & 0.13 & 0.24 & 0.45 & 0.02 & -0.52 & $<0.01$ & -0.58 & $<0.01$ \\
\hline$U$ & -0.48 & $<0.01$ & -0.61 & $<0.01$ & 0.23 & 0.10 & 0.45 & 0.02 & -0.58 & $<0.001$ & -0.58 & $<0.01$ \\
\hline \multicolumn{13}{|c|}{ Summer 2004} \\
\hline$U_{\max }$ & -0.10 & 0.31 & -0.24 & 0.16 & -0.08 & 0.35 & 0.27 & 0.12 & -0.30 & 0.07 & 0.09 & 0.35 \\
\hline$R$ & -0.60 & $<0.01$ & -0.60 & $<0.01$ & 0.69 & $<0.001$ & 0.71 & $<0.01$ & 0.03 & 0.43 & -0.20 & 0.20 \\
\hline$S_{w}$ & 0.49 & $<0.01$ & 0.53 & 0.01 & -0.23 & 0.13 & -0.42 & 0.04 & 0.30 & 0.07 & 0.20 & 0.20 \\
\hline$K_{c}$ & -0.25 & 0.10 & -0.35 & 0.07 & 0.08 & 0.35 & 0.38 & 0.05 & -0.23 & 0.13 & 0.05 & 0.41 \\
\hline$V_{f}$ & -0.23 & 0.13 & -0.38 & 0.05 & -0.03 & 0.43 & 0.27 & 0.12 & -0.38 & 0.03 & -0.13 & 0.29 \\
\hline$U$ & 0.14 & 0.24 & 0.13 & 0.29 & -0.27 & 0.09 & -0.02 & 0.47 & -0.14 & 0.24 & 0.38 & 0.05 \\
\hline
\end{tabular}

Note subset excludes debris dam reaches; bold indicates significance $(p<0.05)$ 
(a)

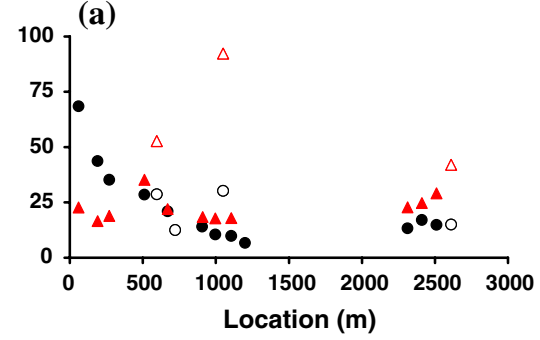

(b)

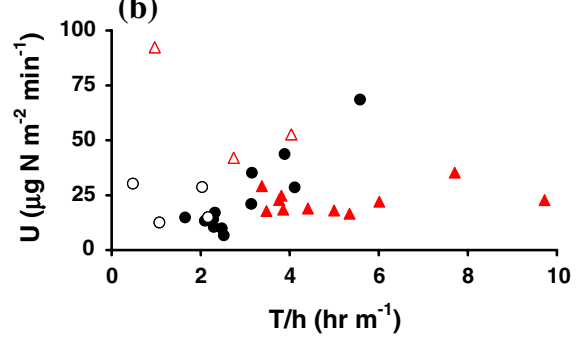

(c)

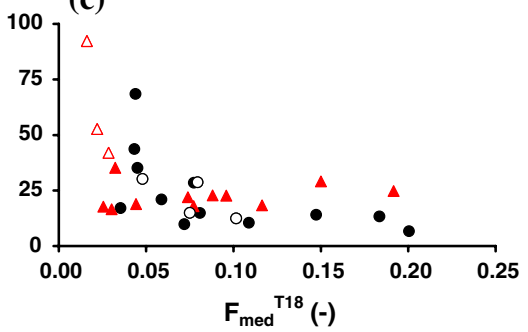

(d)

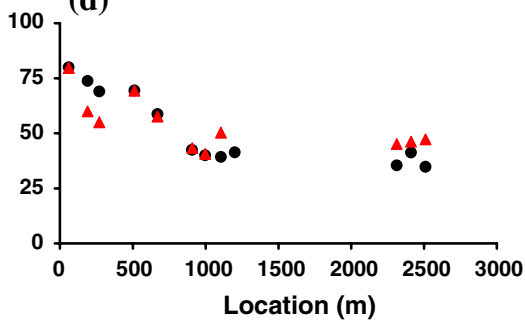

(e)

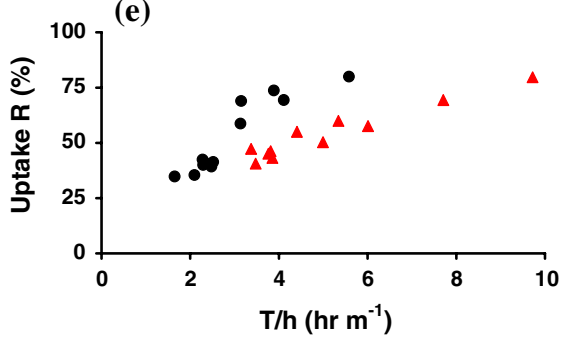

(f)

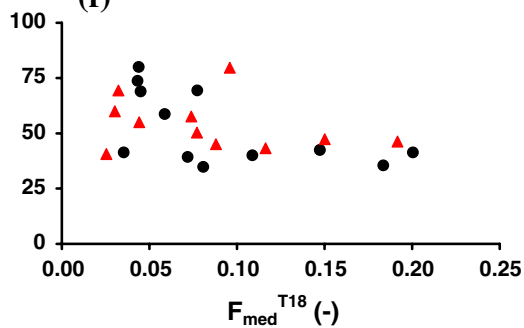

Fig. $5 \mathrm{NH}_{4}{ }^{+}$uptake terms vs. hydrologic and TS terms. Circles are fall 2003; triangles are summer 2004; open symbols are debris dam reaches

summer, when they had high values for $U$ and low values for $F_{m e d}^{T 18}$. Note that debris dams were hydraulically active in fall, but inactive in summer when we observed this pattern.

\section{Discussion}

\section{Concentration profiles and leaf litter}

The difference between fall and summer concentration profiles likely reflects the effect of leaf litter. In fall, immobilization by leaf litter biotic communities is associated with high $\mathrm{NH}_{4}{ }^{+}$uptake (e.g., Tank and Webster 1998), hence low $\mathrm{NH}_{4}^{+}$concentrations. In summer, mineralization of decomposed leaf litter likely resulted in higher $\mathrm{NH}_{4}{ }^{+}$concentrations (as evidenced by debris dam reaches). The downstream increase in $\mathrm{NH}_{4}{ }^{+}$concentrations in summer can be attributed to a likely increase in allochthonous organic matter (e.g., leaf litter), due to downstream transport and enhanced deposition because of downstream decrease in channel gradient. While we did not take actual measurements of organic matter, we did collect DON. DON profiles had a downstream decrease in fall, a flat profile in winter and a downstream increase in summer. This distinct seasonal reversal in DON profiles provides evidence for the seasonal pattern in organic matter distribution.

Effect of stream size, transient storage and debris dams

$\mathrm{NH}_{4}{ }^{+}$uptake is controlled by various physical/ hydrologic, chemical and biological factors, and their relative importance varies with stream size and across seasons. These factors are related, which complicates evaluating their relative importance. Distinct uptake patterns emerged in our study, which can be broadly attributed to a stream size effect and a TS effect but 


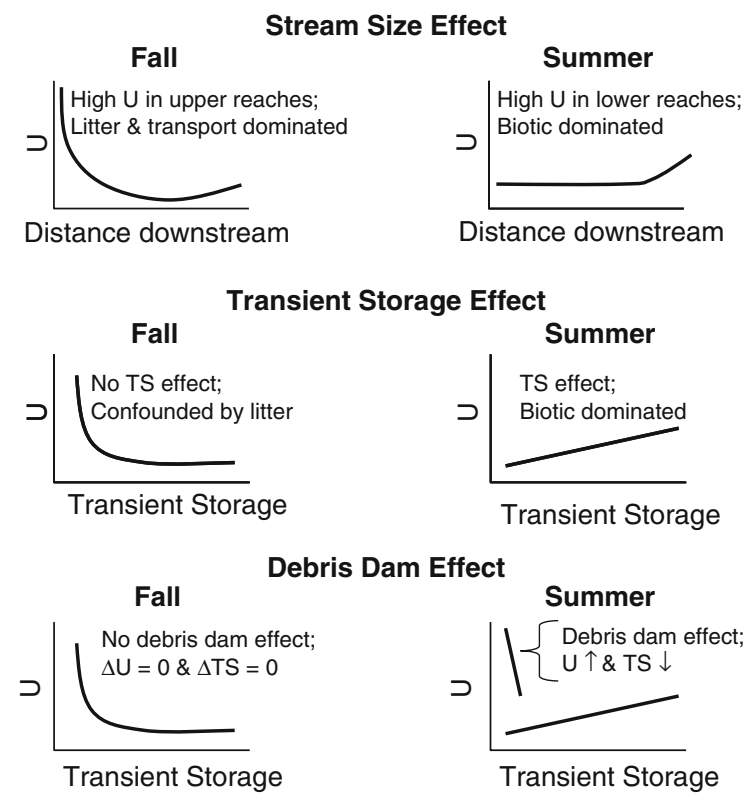

Fig. 6 Summary of the effect of stream size, transient storage and debris dams on $\mathrm{NH}_{4}{ }^{+}$uptake rate

also illustrate the importance of debris dams and leaf litter. We summarize these effects through a seasonal comparison (Fig. 6), as discussed below.

Because $U_{\max }, K_{c}, V_{f}$ and $U$ covaried and behaved similarly in terms of their seasonal comparison and correlation with transport and TS terms, in the discussion below we discuss $U$ only. Also, because $S_{w}$ is largely controlled by advection and to a lesser extend by uptake, we do not discuss this metric. In the discussion below we refer to the subset of nondebris dam reaches only, except when we discuss the effect of debris dams.

\section{How important was the effect of stream size?}

In fall, even though stream temperatures were lower, $U$ was higher. This may be attributed to high rates of biotic immobilization by leaf litter biotic communities and reduced shading by the forest canopy. Also, in fall the positive relationship between $U$ and $T / h$ indicates that transport affected $U$; the more contact there was between water column and streambed (i.e., higher $T / h$ ) the higher $U$ was. Over the same range of $T / h$ in Fig. 5b, fall had a larger range in $U$ (steeper slope). Also, the upper reaches had higher $U$ compared to summer (the middle and lower reaches were similar) (Fig. 5a). For fall, this greater response of $U$ to $T / h$ may be explained by relatively more leaf litter trapped in the smaller cross sections of the upper reaches (i.e., relative to the size of the cross section). For summer, this difference between upper and lower reaches was less pronounced, perhaps because of the breakdown and downstream transport of leaf litter over the course of the year.

Summarized in Fig. 6, the stream size effect in fall reflects the consequences of more leaf litter in upper reaches (biotic control) and increasing discharge in lower reaches (abiotic-transport effect). Uptake rate patterns were mainly controlled by the distribution of leaf litter and associated biotic assimilation, such that uptake rates were higher in upper reaches with greater leaf litter. Lower contact time (as illustrated by $T / h$ ) downstream, also contributed to the lower uptake rates in downstream reaches in the fall. In summer, the stream size effect reflects a biotic dominated rather than transport dominated system; uptake rate patterns were probably controlled by mineralization of decomposed leaf litter coupled with biotic assimilation and nitrification. In summer, hydrologic measures such as $T / h$ and discharge were less important as controls on uptake rate patterns.

$R$ had a strong seasonal correlation. From a systems perspective, this seasonal correlation is intriguing. After all, fall had higher flows, higher velocities and hence less contact between water column and streambed (i.e., lower $T / h$ ). In addition, stream temperatures were lower. Also here, the high $R$ for fall, while having lower contact times and lower stream temperatures, can be explained by the presence of leaf litter. By treating $T / h$ as the dominant physical factor (i.e., water-sediment contact), we can evaluate the effect of leaf litter graphically (Fig. 5e). The relationships are similar to those found for $U$ : for the same range of $T / h$, fall had a larger range in $R$ and this effect was primarily due to elevated $R$ in the upper reaches in fall relative to summer. Hence, even though summer and fall had distinct hydrologic and biologic conditions, there was a strong seasonal correlation in spatial patterns of $R$ between summer and fall. This downstream pattern is similar to patterns of proportional nitrogen removal determined by regional-scale analysis (Howarth et al. 1996; Seitzinger et al. 2002) and reach-scale analysis (Claessens et al. 2009b), which show that nitrogen removal decreases with the inverse of travel time 
over depth. In our longitudinal study of $\mathrm{NH}_{4}{ }^{+}$uptake, examination of the mechanisms involved showed important distinctions between summer and fall and the underlying causes of the stream size effect.

\section{How important was TS on ammonium uptake?}

In fall, the negative relationship between $U$ and $F_{\text {med }}^{T 18}$ suggests that TS reduced uptake rate. This is opposite from what one would expect, as TS exchange (used here as a surrogate for hyporheic exchange) is generally thought to be positively related to nitrogen uptake. Leaf litter is thought to enhance surface TS, which combined with high uptake should exhibit a positive relationship between TS and uptake rate (JL Tank, personal communication; also see Argerich et al. 2008). Our results show the opposite effect. The expected TS effect was absent in fall because it was confounded by the litter dominated system; litter produced higher uptakes, but also may have plugged the streambed, hence high uptake rates were correlated with reduced hyporheic exchange. The inverse relationship in fall between $U$ and TS provides evidence that the leaf litter with its high immobilization rates was the dominant control on uptake and was correlated with reduced hyporheic exchange.

In summer, the TS effect was present as $U$ had a positive relationship with $F_{\text {med }}^{T 18}$; mineralization in the hyporheic zone may have produced higher $\mathrm{NH}_{4}{ }^{+}$ concentrations which stimulated biotic uptake (assimilation and nitrification). In summer, biotic processes dominated uptake patterns and were related to covarying physical factors. We verified that this relationship was not affected by co-variation between $F_{m e d}^{T 18}$ and discharge (results not shown). Therefore, compared to fall, summer TS and its associated biotic activity played a larger role.

This seasonal difference is similar to findings from an extensive study on TS and nutrient uptake by Hall et al. (2002), who reported a positive relationship with $V_{f}$ for summer only (in our study we found a positive relationship of TS with $U$ only; the relationship with $V_{f}$ was not significant). Hall et al. (2002) also addressed the effect of surface water pools on TS estimates (in contrast to true hyporheic exchange); our results showed a similar effect where leaf litter reduced hyporheic exchange, but also created some local pooling of water (based on visual observations). Other studies relating TS and nutrient uptake have been equivocal (Hall et al. 2002; Roberts et al. 2007), showing negative (Valett et al. 2002), neutral (Martí et al. 1997; Butturini and Sabater 1999; Simon et al. 2005) and positive effects (Valett et al. 1996; Mulholland et al. 1997; Argerich et al. 2008). Our results suggest that the effect of TS on $\mathrm{NH}_{4}{ }^{+}$uptake was confounded by leaf litter and debris dams (discussed below). It would be worthwhile to assess whether other studies relating TS and nutrient uptake were similarly affected by the confounding effect of organic matter and other fine particulates, which might have increased uptake rates but reduced hyporheic exchange.

Overall, in our study TS had only a small but significant effect on uptake rate and only during the summer. The TS values were moderately high (e.g., see Runkel 2002), but had a small range of variation, which could explain their small effect on uptake. Our results are consistent with Boulton et al. (1998) who argue that hyporheic exchange is generally considered least important in headwater streams and tends to peak in intermediate streams.

\section{How important were debris dams on ammonium uptake?}

In fall, debris dams had no distinct effect on uptake or TS, although the debris dams were hydraulically active. This may reflect their recent formation ( 2 months prior) and thus limited trapping of sediment and particulate organic matter. In summer, the debris dam effect was significant; although the debris dams were hydraulically inactive then, the upstream reaches had significantly higher uptake rates (2-5 fold) and lower TS exchange. Higher uptake rates in the debris dam reaches indicate high rates of biotic activity (including both mineralization and uptake), that may be stimulated by additional availability of organic matter. Two of the three debris dam reaches had higher $\mathrm{NH}_{4}{ }^{+}$concentrations, which suggests higher rates of mineralization. High rates of mineralization and uptake can be coupled, reflecting overall high rates of microbial activity (Jones et al. 1995). This provides evidence that the debris dams' relic function in trapping particulate organic matter had transformed the upstream reaches into transient hot spots of biogeochemical cycling. This was also shown by Groffman et al. (2005), who compared different geomorphic structures within Baisman Run 
and other suburban streams; using sediment samples and laboratory incubation they found that debris dams had two orders of magnitude larger denitrification potential than riffles. In summer, the debris dam reaches also reduced TS, which may reflect increased plugging of streambed associated with accumulated (through year) slowing and trapping of material by the debris dam. The summer debris dam effect is similar to the leaf litter effect in the fall, where the availability of organic material increases uptake rates but also correlates with reduced TS.

Thus, for reach scale studies on biogeochemical cycling it is necessary to account for the temporally, transient functioning of debris dams and other episodic geomorphic structures. For watershed scale studies, additional aspects that have to be considered are the temporal and spatial frequency of debris dams and their upstream hydraulic influence. Valett et al. (2002) examined the spatial frequency of debris dams and their effect on phosphate uptake within the context of forest succession, and found that debris dam frequency increased uptake. Interestingly, they also found an inverse relationship between $V_{f}$ and TS, which in our study we relate to the above described confounding effect from the deposition of fine organic particulates. While one could argue that the net effect of debris dams on $\mathrm{NH}_{4}{ }^{+}$uptake is perhaps negligible (they serve as both source and sink), their importance for other biogeochemical processes, in particular denitrification, may be substantial. In fact, accounting for the effect of debris dams and other organic debris can be essential for elucidating temporal patterns of watershed nitrogen export, as was illustrated by Bernhardt et al. (2003, 2005).

\section{Conclusions}

Our results showed distinct seasonality in longitudinal $\mathrm{NH}_{4}{ }^{+}$uptake patterns and important differences in how these uptake patterns were affected by organic matter influences, stream size, TS and debris dams. There was a distinct reversal in uptake patterns, with fall having the highest uptake rates in the upper reaches and summer having the highest uptake rates in the lower reaches. And while proportional uptake patterns were similar in fall and summer, the controlling mechanisms were different. This seasonal shift in the relative importance of litter processing and subsequent microbial heterotrophic production on $\mathrm{NH}_{4}{ }^{+}$uptake patterns suggests longitudinal biotic adjustments that conform to the river continuum concept (Vannote et al. 1980), which describes a longitudinal gradient in physical conditions resulting in a continuum of biotic adjustments and associated uptake patterns.

Nutrient spiraling theory is inherently spatial. However, the common approach for deriving spiraling metrics (i.e., nutrient addition experiments on single reaches) is aspatial, and most (comparison) studies do not necessarily address the spatial connectivity of stream networks as conduits of organic matter and nutrients. Similarly, current practices in scaling nutrient cycling across large-scale stream networks are based on a static interpretation of uptake patterns, because they do not necessarily scale the causal factors of nitrogen uptake (e.g., organic matter dynamics), but rather base the scaling on derived uptake/removal rates or other spiraling metrics. Recent examples of scaling studies include Wollheim et al. (2006) (using $V_{f}$ ) and Ensign and Doyle (2006) (using $U$ ). These integrative analyses can be useful for understanding nutrient cycling at large temporal and spatial scales. The results from our study, however, show that to examine nitrogen spiraling or removal along the stream size spectrum, or within a larger spatial/network context, it is critical to address spatial linkages between carbon cycling and nitrogen cycling, including seasonal and longitudinal differences in organic matter availability, and the effects of stream size, hyporheic functioning and debris dam activity. Scaling these drivers of nitrogen uptake is difficult, because of limited empirical observations (Wipfli et al. 2007) and a lack of quantitative modeling frameworks. Our study is one of few empirical studies that examined nitrogen processing along a channel corridor. To our knowledge, no empirical study has addressed aspects of nitrogen cycling within a larger, stream network perspective. Such experiments are necessary to advance our understanding of landscape and waterscape linkages between hydrology, nitrogen and carbon cycling, as to elucidate the critical controls on watershed nitrogen export.

Finally, in our study stream, the seasonal and longitudinal differences in $\mathrm{NH}_{4}^{+}$uptake reflect interactions between flow conditions and the role of leaf litter and other organic debris. Urbanization can 
alter both of these characteristics. Development can change the delivery of organic particulates to streams (Belt et al. 2007) and can also produce flow characteristics that alter the downstream transport and deposition of organic matter, both spatially and temporally (Wipfli et al. 2007). Our research suggests that interpreting the impact of these changes requires characterizing seasonal shifts in the longitudinal patterns and dominant controls on in-stream nitrogen cycling processes. The role of debris dams and transient storage, for example, were significantly different for summer and fall conditions and illustrate the limitations of static interpretations of the role that these channel features play. Understanding and characterizing these patterns and dynamics are particularly important for targeting stream- and/or watershed restoration efforts.

Acknowledgments We thank BES-LTER and Cary Institute of Ecosystems Studies for help with field experiments and laboratory analysis; UMD Palmer Lab for use of field equipment; and MBL Ecosystems Center for use of ion chromatograph. Special thanks to Joanna York and BES-LTER staff and student volunteers for assistance with fieldwork, including Dan Dillon, Melody Hicks, Tara Krebs, Kristen O'Grady and Andrea Taylorson. Comments by two anonymous reviewers helped to improve this manuscript. Funding for this research was provided by: NASA Earth System Science Fellowship; NSF Doctoral Dissertation Research Improvement grant (No. 0302703); NSF Long Term Ecological Research project (DEB-0423476); and San Diego State University Shared Visions grant.

Open Access This article is distributed under the terms of the Creative Commons Attribution Noncommercial License which permits any noncommercial use, distribution, and reproduction in any medium, provided the original author(s) and source are credited.

\section{References}

Alexander RB, Smith RA, Schwarz GE (2000) Effect of stream channel size on the delivery of nitrogen to the Gulf of Mexico. Nature 403:758-761

Alexander RB, Boyer EW, Smith RA, Schwarz GE, Moore RB (2007) The role of headwater streams in downstream water quality. J AmWater Resour Assoc 43:41-59

Argerich A, Martí E, Sabater F, Ribot M, von Schiller D, Riera JL (2008) Combined effects of leaf litter inputs and a flood on nutrient retention in a Mediterranean mountain stream during fall. Limnol Oceanogr 53:631-641

Belt KT, Kaushal SS, Swan CM, Pouyat RV, Groffman PM, Turcsanyi I, Greenwood W (2007) Altered urban hydrology: effects on the transport of organic matter in streams. Paper presented at the Ecological Society of America 2007 Annual Meeting, San Jose, CA

Bencala KE, Walters RA (1983) Simulation of solute transport in a mountain pool-and-riffle stream: a transient storage model. Water Resour Res 19:718-724

Bernhardt ES, Likens GE, Buso DC, Driscoll CT (2003) Instream uptake dampens effects of major forest disturbance on watershed nitrogen export. Proceedings of the National Academy of Sciences of the United States of America 100:10304-10308

Bernhardt ES, Likens GE, Hall RO, Buso DC, Fisher SG, Burton TM, Meyer JL, McDowell WH, Mayer MS, Bowden WB, Findlay SEG, Macneale KH, Stelzer RS, Lowe WH (2005) Can't see the forest for the stream? Instream processing and terrestrial nitrogen exports. Bioscience 55:219-230

Bilby RE, Likens GE (1980) Importance of organic debris dams in the structure and function of stream ecosystems. Ecology 61:1107-1113

Boulton AJ, Findlay S, Marmonier P, Stanley EH, Valett HM (1998) The functional significance of the hyporheic zone in streams and rivers. Annu Rev Ecol Syst 29: 59-81

Butturini A, Sabater F (1999) Importance of transient storage for ammonium and phosphate retention in a sandy-bottom Mediterranean stream. Freshw Biol 41:593-603

Claessens L, Tague CL (2009) A transport-based method for estimating in-stream nitrogen uptake at ambient concentration from nutrient addition experiments. Limnology and Oceanography: methods (in press)

Claessens L, Tague CL, Groffman PM, Melack JM (2009a) Longitudinal assessment of the effect of concentration on stream $\mathrm{N}$ uptake rates in an urbanizing watershed. Biogeochemistry. doi:10.1007/s10533-009-9376-y

Claessens L, Tague CL, Band LE, Groffman PM, Kenworthy ST (2009b) Hydro-ecological linkages in urbanizing watersheds: an empirical assessment of in-stream nitrate loss and evidence of saturation kinetics. J Geophys ResBiogeosci. doi:10.1029/2009JG001017

Dodds WK, Lopez AJ, Bowden WB, Gregory S, Grimm NB, Hamilton SK, Hershey AE, Martí E, McDowell WH, Meyer JL, Morrall D, Mulholland PJ, Peterson BJ, Tank JT, Valett HM, Webster JR, Wollheim W (2002) N uptake as a function of concentration in streams. J North Am Benthol Soc 21:206-220

Elwood JW, Newbold JD, O’Neill RV, VanWinkle W (1983) Resource spiraling: an operational paradigm for analyzing lotic ecosystems. In: Fontaine TD, Bartell SM (eds) Dynamics of lotic ecosystems. Ann Arbor Science, Ann Arbor, MI, pp 3-27

Ensign SH, Doyle MW (2006) Nutrient spiraling in streams and river networks. J Geophys Res-Biogeosci 111: G04009

Fenessy MS, Cronk JK (1997) The effectiveness and restoration potential of riparian ecotones for the management of nonpoint source pollution, particularly nitrate. Crit Rev Environ Sci Technol 27:285-317

Groffman PM, Bain DJ, Band LE, Belt KT, Brush GS, Grove JM, Pouyat RV, Yesilonis IC, Zipperer WC (2003) Down by the riverside: urban riparian ecology. Front Ecol Environ 6:315-321 
Groffman PM, Law NL, Belt KT, Band LE, Fisher GT (2004) Nitrogen fluxes in urban watershed ecosystems. Ecosystems 7:393-403

Groffman PM, Dorsey AM, Mayer PM (2005) N processing within geomorphic structures in urban streams. J North Am Benthol Soc 24:613-625

Groffman PM, Pouyat RV, Cadenasso ML, Zipperer WC, Szlavecz K, Yesilonis IC, Band LE, Brush GS (2006) Land use context and natural soil controls on plant community composition and soil nitrogen and carbon dynamics in urban and rural forests. For Ecol Manag 236:177-192

Hall RO, Bernhardt ES, Likens GE (2002) Relating nutrient uptake with transient storage in forested mountain streams. Limnol Oceanogr 47:255-265

Hammer TR (1972) Stream channel enlargement due to urbanization. Water Resour Res 8:1530-1540

Howarth RW, Billen G, Swaney D, Townsend A, Jaworski N, Lajtha K, Downing JA, Elmgren R, Caraco N, Jordan T, Berendse F, Freney J, Kudeyarov V, Murdoch P, Zhu Z-L (1996) Regional nitrogen budgets and riverine $\mathrm{N}$ and $\mathrm{P}$ fluxes for the drainages to the North Atlantic Ocean: natural and human influences. Biogeochemistry 35:75139

Jones JB, Mulholland PJ (eds) (2000) Streams and ground waters. Academic Press, San Diego

Jones JB, Fisher SG, Grimm NB (1995) Nitrification in the hyporheic zone of a desert stream ecosystem. J North Am Benthol Soc 14:249-258

Kaushal SS, Groffman PM, Mayer PM, Striz E, Doheny EJ, Gold AJ (2008) Effects of stream restoration on denitrification at the riparian-stream interface of an urbanizing watershed of the mid-Atlantic U.S. Ecol Appl 18:789-804

Kendall MG (1975) Rank correlation methods. Charles Griffin, London

Leopold LB (1968) Hydrology for urban landplanning-a guidebook on the hydrologic effects of urban land use. US Geol Surv Circ 554:18

Martí E, Grimm NB, Fisher SG (1997) Pre- and post-flood retention efficiency of nitrogen in a Sonoran Desert stream. J North Am Benthol Soc 16:805-819

McClain ME, Boyer EW, Dent CL, Gergel SE, Grimm NB, Groffman PM, Hart SC, Harvey JW, Johnston CA, Mayorga E, McDowell WH, Pinay G (2003) Biogeochemical hot spots and hot moments at the interface of terrestrial and aquatic ecosystems. Ecosystems 6:301-312

Mulholland PJ, Marzolf ER, Webster JR, Hart DR, Hendricks SP (1997) Evidence that hyporheic zones increase heterotrophic metabolism and phosphorus uptake in forest streams. Limnol Oceanogr 42:443-451

Mulholland P, Hall R, Hamilton S, Peterson B, Tank J, Ashkenas L, Cooper L, Dahm C, Dodds W, Findlay S, Gregory S, Grimm N, Johnson S, McDowell W, Meyer J, Poole G, Valett M, Webster J et al (2008) Stream denitrification across biomes and its response to anthropogenic nitrate loading. Nature 458:202-205

Newbold JD, Elwood JW, O'Neill RV, Van Winkle W (1981) Measuring nutrient spiraling in streams. Can J Fish Aquat Sci 38:860-863

Paul MJ, Meyer JL (2001) Streams in the urban landscape. Annu Rev Ecol Syst 32:333-365
Peterson BJ, Wollheim WM, Mulholland PJ, Webster JR, Meyer JL, Tank JL, Martí E, Bowden WB, Valett HM, Hershey AE, McDowell WH, Dodds WK, Hamilton SK, Gregory S, Morrall DD (2001) Control of nitrogen export from watersheds by headwater streams. Science 292:8690

Roberts BJ, Mulholland PJ, Houser JN (2007) Effects of upland disturbance and instream restoration on hydrodynamics and ammonium uptake in headwater streams. J North Am Benthol Soc 26:38-53

Runkel RL (1998) One dimensional transport with inflow and storage (OTIS): a solute transport model for streams and rivers. U.S. Geological Survey Water-Resources Investigation Report 98-4018. p 73

Runkel RL (2002) A new metric for determining the importance of transient storage. J North Am Benthol Soc 21: 529-543

Seitzinger SP, Styles RV, Boyer EW, Alexander RB, Billen G, Howarth RW, Mayer B, van Breemen N (2002) Nitrogen retention in rivers: model development and application to watersheds in the northeastern U.S.A. Biogeochemistry 57/58:199-237

Simon KS, Townsend CR, Biggs BJF, Bowden WB (2005) Temporal variation of $\mathrm{N}$ and $\mathrm{P}$ uptake in 2 New Zealand streams. J North Am Benthol Soc 24:1-18

Smith RA, Schwarz GE, Alexander RB (1997) Regional interpretation of water-quality monitoring data. Water Resour Res 33:2781-2798

Stream Solute Workshop (1990) Concepts and methods for assessing solute dynamics in stream ecosystems. J North Am Benthol Soc 9:95-119

Tank JL, Webster JR (1998) Interactions of substrate and nutrient availability on wood biofilm processes in streams. Ecology 79:151-162

Valett HM, Morrice JA, Dahm CN, Campana ME (1996) Parent lithology, surface-groundwater exchange, and nitrate retention in headwater streams. Limnol Oceanogr 41:333-345

Valett HM, Crenshaw CL, Wagner PF (2002) Stream nutrient uptake, forest succession, and biogeochemical theory. Ecology 83:2888-2901

Valett HM, Thomas SA, Mulholland PJ, Webster JR, Dahm CN, Fellows CS, Crenshaw CL, Peterson CG (2008) Endogenous and exogenous control of ecosystem functioning: $N$ cycling in headwater streams. Ecology 89: 3515-3527

Vannote RL, Minshall GW, Cummins KW, Sedell JR, Cushing CE (1980) River continuum concept. Can J Fish Aquat Sci 37:130-137

Walsh CJ, Roy AH, Feminella JW, Cottingham PD, Groffman PM, Morgan RP (2005) The urban stream syndrome: current knowledge and the search for a cure. J North Am Benthol Soc 24:706-723

Webster JR, Ehrman TP (1996) Solute dynamics. In: Hauer FR, Lamberti GA (eds) Methods in stream ecology. Academic Press, San Diego, pp 145-160

Webster JR, Patten BC (1979) Effects of watershed perturbation on stream potassium and calcium dynamics. Ecol Monogr 49:51-72

Wipfli MS, Richardson JS, Naiman RJ (2007) Ecological linkages between headwaters and downstream ecosystems: 
transport of organic matter, invertebrates, and wood down headwater channels. J AmWater Resour Assoc 43:72-85. doi:10.1111/j.1752-1688.2007.00007.x

Wollheim WM, Peterson BJ, Deegan LA, Hobbie JE, Hooker B, Bowden WB, Edwardson KJ, Arscott DB, Hershey AE (2001) Influence of stream size on ammonium and suspended particulate nitrogen processing. Limnol Oceanogr 46:1-13

Wollheim WM, Vörösmarty CJ, Peterson BJ, Seitzinger SP, Hopkinson CS (2006) Relationship between river size and nutrient removal. Geophys Res Lett 33:L06410. doi: 10.1029/2006GL025845 